\title{
Consumo de combustível e emissões de poluentes em um motor Diesel convertido a etanol para geração térmica de energia elétrica
}

\section{Fuel consumption and pollutant emissions of a Diesel engine converted to run on ethanol for electric thermal energy generation}

\author{
Vinícius Rückert Roso ${ }^{1}$; Macklini Dalla Nora ${ }^{2}$; Mario Eduardo Santos Martins ${ }^{3}$; Paulo Romeu \\ Moreira Machado ${ }^{4}$
}

\begin{abstract}
Resumo
Nos esforços globais para a minimização nas emissões de gases do efeito estufa e redução da pegada de carbono, combustíveis renováveis têm sido extensivamente utilizados em substituição aos combustíveis fósseis nos motores de combustão interna. Particularmente para geração de energia elétrica local, motores diesel são os mais utilizados devido à elevada eficiência térmica e a robustez, se comparado a motores de ignição por centelha. Entretanto, estes sistemas apresentam elevados níveis de emissões de óxido de nitrogênio (NOx) e material particulado, trazendo sérias consequências para o meio ambiente. Assim, esta pesquisa combina simulação computacional e resultados experimentais da conversão de um motor diesel para a operação com etanol, sendo sua utilização na geração de energia elétrica. Como este combustível renovável é largamente produzido no Brasil utilizando a cana-de-açúcar, acaba por possuir seu custo reduzido em especial próximo à produtores e refinarias. Dados experimentais foram utilizados na validação do modelo computacional unidimensional desenvolvido para a conversão, onde resultados foram analisados para a comparação de ambos combustíveis. Análises econômicas para diferentes condições de carga forneceram informações de custos operacionais em locais próximos às fontes de produção de etanol. Os resultados apontam as vantagens no uso do combustível renovável para a geração de energia elétrica, como o custo reduzido e a menor emissão de NOx ao longo de toda a gama de operação.
\end{abstract}

Palavras-chave: Etanol. Gerador de Energia. Custo de Energia.

\begin{abstract}
In the global effort to minimize emissions of greenhouse gases and decrease the carbon footprint, renewable fuels are being extensively used to replace fossil fuels in internal combustion engines. Particularly in the field of local power generation, Diesel engines are by far the most used units due to their higher thermal efficiency and robustness compared to spark-ignition engines. However, such power systems have usually large emissions of oxides of nitrogen (NOx) and soot, which poses serious harm to the environment. Therefore, the present research combines computational simulation and experimental results to convert a power generation set from diesel to ethanol operation. As this renewable fuel is largely produced from sugarcane in Brazil, it becomes cheaper than diesel for standalone applications especially close to crops and refineries. Experimental data was used to validate a one-dimensional computational model developed for the conversion, while results from gaseous emissions were measured and analysed comparing both fuels.
\end{abstract}

\footnotetext{
${ }^{1}$ Aluno de mestrado do Programa de Pós Graduação em Engenharia de Produção, Universidade Federal de Santa Maria; vinicius. roso@mecanica.ufsm.br

${ }^{2}$ Aluno de doutorado do Departamento de Engenharia Mecânica, Brunel University London; mack.formula@gmail.com

${ }^{3}$ Professor Adjunto do Departamento de Engenharia Mecânica da Universidade Federal de Santa Maria - UFSM; mario@, mecanica.ufsm.br

${ }^{4}$ Professor Adjunto do Departamento de Engenharia Mecânica da Universidade Federal de Santa Maria - UFSM; promeu. machado@gmail.com
} 
A cost-benefit analysis was conducted at several power requirements to provide meaningful monetary figures regarding the fuel conversion to be used near ethanol production sites. The results demonstrated energy cost advantages on using this renewable fuel for power generation, while keeping significant lower NOx emissions throughout the whole operation range.

Keywords: Ethanol. Power Generation. Energy Cost.

\section{Introdução}

O constante aumento da temperatura global tem alertado os cientistas quanto à queima de combustíveis fósseis e a consequente produção de gases de efeito estufa. Mantidas as tendências atuais, pesquisas mostram que as emissões provenientes dos setores de energia e de transportes podem aumentar em 97\% até 2030 (BUSTAMANTE, 2013). A consciência destes fatores, aliada ao crescimento da economia, da atividade industrial e, consequentemente, da demanda de energia elétrica, tem promovido a busca por fontes limpas e renováveis de produção de energia a vários anos (HEYWOOD, 1988).

Especificamente no Brasil, um fato agravante refere-se ao incremento no número de geradores movidos a óleo diesel, principalmente após o "apagão do setor elétrico" ocorrido em 2001. A solução que seria apenas temporária adquiriu caráter permanente na indústria, no comércio e até em residências, devido à variação existente no sistema tarifário, no qual o preço cobrado pela energia elétrica difere de acordo com horários e estações do ano (CCST, 2013).

Segundo alguns fabricantes de grupos geradores no país, a expectativa era de que em 2013, o aumento das vendas chegasse a $30 \%$ em relação a 2012, sendo consumidores potenciais os pequenos produtores rurais, que dependem da energia para garantir a integridade de sua produção (BARROS, 2010). Este perfil crescente é confirmado pelo aumento da geração de energia elétrica através de meios não renováveis, de 15,5\% em 2012 para 20,7\% em 2013 (MME, 2014). Também na zona rural, estima-se que haja 20 milhões de habitantes vivendo em áreas isoladas não atendidas pelo sistema interligado de energia, dependendo, em grande maioria, de geradores a óleo diesel para produção de energia elétrica (BERNARDES, 2007).
Por outro lado, a sustentabilidade dos motores de combustão interna vem sendo incentivada no Brasil desde os anos 1970, quando o governo criou o Programa Nacional do Álcool (Próalcool) a fim de substituir os motores automotivos movidos à gasolina por motores movidos exclusivamente a etanol. Entretanto, em meados dos anos 1980, em função da situação econômica do País e da inflação existente na época, reduziram-se as subvenções para produção do etanol que, aliada à redução no preço internacional do petróleo em mais de $60 \%$ e ao aumento do preço do açúcar, fizeram com que fosse mais rentável aos usineiros a produção do adoçante ao invés do combustível. Dessa forma, para os consumidores o uso do combustível derivado do petróleo se tornou mais vantajoso que o etanol (KOHLHEPP, 2010).

Entretanto, em decorrência do apelo ao desenvolvimento tecnológico representado pelos motores "flexfuel", o etanol voltou a figurar no cenário dos motores de combustão interna, fazendo com que mais de um terço dos veículos da frota nacional em 2014 pudesse empregá-lo como combustível (DENATRAN, 2014). No entanto, para geração térmica de energia elétrica por grupos geradores, o diesel ainda é o combustível mais utilizado.

De acordo com estudos realizados pela Agência Nacional do Petróleo (ANP, 2014), o etanol é vendido em todas as regiões brasileiras a um valor inferior ao diesel. A maior diferença é encontrada na Região Sudeste e descrita historicamente como mostra a Figura 1. A ocorrência deste fato é justificada pela região ser responsável por mais de $67 \%$ da produção de cana-de-açúcar do País (IBGE, 2012). De acordo com Seleghim Jr. e Polikarpov (2009), a produção de etanol através da cana-de-açúcar, além de ser técnica e economicamente viável, apresenta os menores índices de $\mathrm{CO}_{2}$ se comparada a outras fontes. 
O uso de 1 joule (J) de energia (fóssil ou renovável) é capaz de produzir 9,3 joules de etanol de cana-de-açúcar. Com a mesma quantidade de energia, poder-se-iam produzir apenas 2 joules de etanol de beterraba ou de trigo. Assim, se comparada a outras culturas agrícolass, a cana-de-açúcar é a melhor fonte de matéria-prima para se produzir etanol (VIEIRA JUNIOR, 2008).

Entretanto, a viabilidade de se utilizar etanol é relativamente prejudicada, pois o consumo volumétrico de combustível acaba sendo superior ao do diesel de petróleo, já que o poder calorífico do etanol encontra-se na faixa de $26 \mathrm{MJ} / \mathrm{kg}$, enquanto que o do diesel é aproximadamente de $42 \mathrm{MJ} / \mathrm{kg}$ (HEYWOOD, 1988). Uma alternativa é o uso de etanol em substituição ao diesel para produtores que sejam capazes de gerar seu próprio combustível. Além da cana-de-açúcar, Rizato (2009) apresenta outras culturas rentáveis para a produção de etanol, caso do aipim que já foi utilizado na década de 1970. De acordo com Cabello (2005), a viabilidade produtiva de etanol é real com custos de $\mathrm{R} \$ 0,438$ por litro utilizando o aipim como matéria-prima e R\$0,392 por litro a partir da cana de açúcar. Apesar dos custos serem variáveis em função das instalações necessárias e do prazo estimado para retorno destes investimentos, são importantes alternativas para produtores que desejam produzir o combustível consumido pelos seus equipamentos.

Outra alternativa, de acordo com Seleghim Jr. e Polikarpov (2009), diz respeito a uma usina que atualmente extrai 45 mil litros de etanol por 500 toneladas de cana-de-açúcar, gerando 150 toneladas de bagaço. Em face as novas tecnologias, pode produzir mais 42 mil litros de etanol de segunda geração, ou seja, a produção de etanolé praticamente dobrada, sem o aumento da área de plantio.

Apesar do etanol ter frações adicionadas à gasolina brasileira, o mesmo não ocorre ao diesel comercializado devido, basicamente, à insolubilidade do etanol no combustível fóssil. Por isso, a utilização do etanol em motores de ignição por compressão limita-se a processos onde ocorra a substituição completa do combustível ou em utilização paralela ao combustível principal. Entre outros autores, Noguchi (1996) desenvolve um motor bicombustível, onde o etanol é transportado até a câmara de combustão juntamente com o ar admitido. Ajav (1998) e Ajav (1999) apresenta dois métodos distintos de utilização de etanol em conjunto com o diesel em motores de ignição por compressão: o primeiro deles utilizando o etanol vaporizado como um combustível suplementar e o segundo misturando pequenas frações de etanol ao diesel.

Figura 1 - Comparativo entre os valores anuais médios dos combustíveis entre os anos de 2009 e 2013 na Região Sudeste do Brasil.

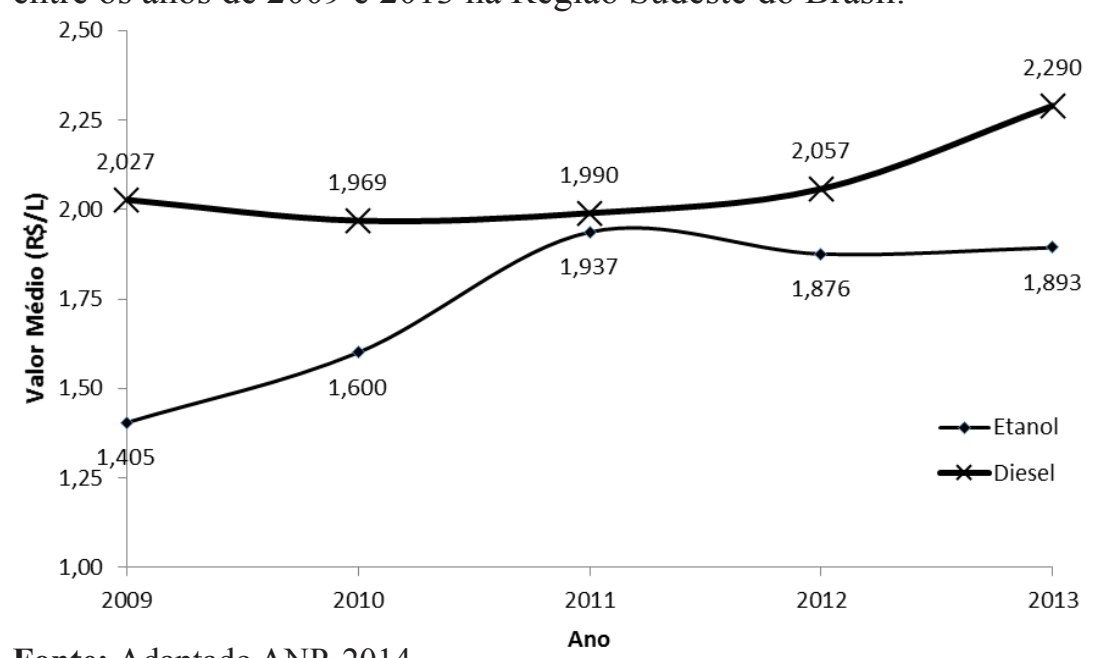

Fonte: Adaptado ANP, 2014. 
Para fins comparativos, neste trabalho são realizados ensaios de consumo de combustível e emissões de poluentes em um mesmo motor operando em diversas condições de carga, sendo o combustível original completamente substituído pelo etanol. Apesar das adaptações necessárias no motor para que opere com os diferentes combustíveis, dados geométricos e construtivos permanecem inalterados, possibilitando comparações do custo de operação de um motor originalmente projetado para operar em ciclo Diesel e posteriormente adaptado para operação em ciclo Otto para utilização de, etanol como combustível.

\section{Materiais e Métodos}

O objeto utilizado para a realização de ensaios experimentais e para a modelagem computacional foi um motor Cummins 3.92 L, 4 cilindros em linha e turboalimentado, originalmente operando com óleo diesel combustível, e conectado a um gerador de energia elétrica ao qual são impostas diferentes cargas, conforme Figura 02. As cargas no gerador foram emuladas através de um conversor "back to back", utilizando-se um retificador com modulação por largura de pulso (PWM) junto ao gerador, e um inversor PWM na rede de energia. Assim, garante-se que a energia elétrica que chegar à rede estará na mesma frequência e tensão, não ocorrendo defasagem entre o gerador e a rede. A injeção de diesel foi controlada através de um sistema eletrônico responsável por manter o motor operando a rotação constante de 1800 RPM, resultando em frequência compatível com a rede brasileira $(60 \mathrm{~Hz})$. Assim, a carga aplicada ao motor em estudo foi variada assumindo-se valores entre $10 \mathrm{~kW}$ e $50 \mathrm{~kW}$, com incremento de $10 \mathrm{~kW}$. Através de uma placa de aquisição de dados, os demais parâmetros de operação foram coletados e sincronizados, para que se armazenassem as informações a cada instante de funcionamento.

A instrumentação completa do motor garante que todos os dados operacionais sejam visualizados e armazenados, tornando possível uma análise posterior. Para isso, os dados devem ser sincronizados, garantindo que além de informações referentes à temperatura e pressão, hajam também informações do posicionamento do virabrequim no instante da coleta. Um sensor indutivo em conjunto com uma roda dentada processou dados relacionados ao posicionamento angular do virabrequim, permitindo o sincronismo das informações adquiridas. Na câmara de combustão, um sensor piezoelétrico foi responsável por enviar os sinais referentes à pressão dentro do cilindro. Dados de pressão também foram obtidos nos coletores de admissão e escape, permitindo, em conjunto com os dados de pressão no cilindro, a realização da modelagem TPA (Three Pressure Analysis). Temperaturas em pontos de admissão de combustível e ar, além de pontos de exaustão, foram monitoradas através de termopares. Dados como a vazão mássica de ar e a razão entre ar e combustível foram mensurados através de dispositivos específicos, como sonda lambda e sensor para fluxo de massa de ar. O volume de combustível consumido foi verificado através de buretas com volume de $500 \mathrm{ml}$, onde a média de 3 aquisições para cada condição de operação resultou no valor adotado para o consumo de combustível. A análise dos gases resultantes da combustão foi realizada através de um equipamento Alfatest ${ }^{\circledR}$, modelo Discovery G4. Todas as aquisições de dados foram realizadas com o motor em temperatura de operação e rotação estável. A vinculação dos sensores à uma placa de aquisição de dados possibilitou que as temperaturas, pressões e vazões pudessem ser sincronizadas e referenciadas ao posicionamento angular do virabrequim. Sequentes aquisições de dados garantem a fidelidade dos valores coletados nos ensaios.

Figura 2 - Grupo motor gerador utilizado no estudo

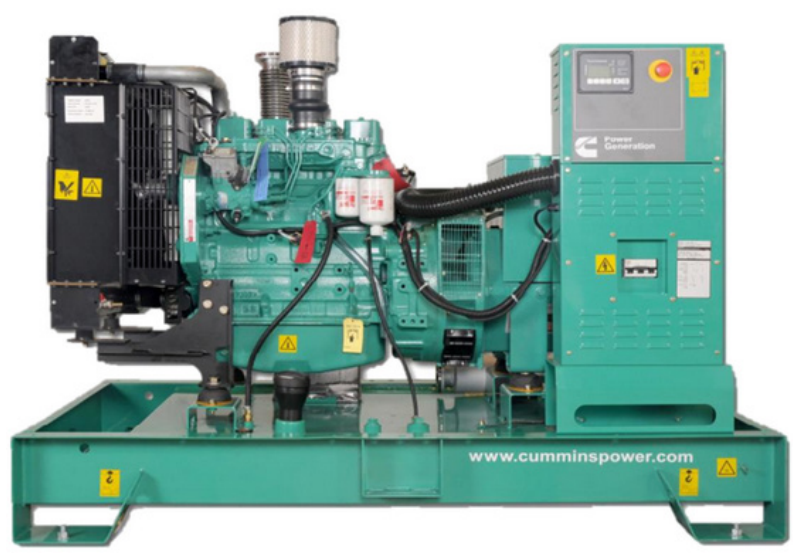

Fonte: Cummins ${ }^{\circledR}$ Inc. (2004) 
Foi realizada uma substituição completa na injeção de diesel pela injeção de etanol como combustível único, onde alterações foram necessárias a fim de que o ciclo de operação do motor fosse alterado de Diesel para Otto. Dentre as modificações realizadas estão a colocação de eletroválvulas injetoras de combustível, velas e demais mecanismos responsáveis pela injeção e ignição adequada ao novo combustível.

Foi desenvolvido um modelo computacional para a verificação dos resultados obtidos experimentalmente e simulação de valores não mensurados de forma experimental. Para que o modelo possa representar o motor de forma fidedigna, além das características descritas em Cummins ${ }^{\circledR}$ Inc. (2004), tornou-se imprescindível o uso de instrumentação adequada para obtenção de dados experimentais de consumo, pressões, temperaturas, vazões e emissões.

Os combustíveis utilizados nos ensaios foram aqueles encontrados comercialmente no Brasil e têm suas propriedades apontadas pela ANP, possuindo o óleo diesel B5 uma fração de 5\% em volume de biodiesel. Já o etanol possui $6 \%$ de água. (ANP, 2005, 2011). Visando minimização de erro, o consumo de combustível relatado como resultado é a média entre cinco leituras realizadas em dispositivo calibrado para cada nível de potência.

A aquisição de dados práticos e teóricos culminou na elaboração do modelo computacional do motor por meio do software GT-Power ${ }^{\circledR}$, posteriormente aprimorado para as alterações de combustível. Na Figura 3 é demonstrado o modelo, onde são representados de forma unidimensional os quatro cilindros, com os respectivos sistemas de admissão e exaustão.

Representando os quatro cilindros do motor, seus respectivos dutos e componentes de admissão e exaustão, o modelo foi processado através de cálculo numérico das equações de conservação de energia, de massa e de momento, as quais descreveram o comportamento dos motores de combustão interna. Assim, utilizando rotação constante, o programa faz inúmeras iterações em cada ciclo do motor (duas voltas do virabrequim) e compara o resultado desse ciclo com o anterior, aplicando critério de convergência. Este critério é então executado no final de cada ciclo para um determinado parâmetro selecionado como, por exemplo, a vazão mássica de ar. Estando o critério satisfeito, a simulação converge e este último valor do parâmetro é tido como resultado final.

\section{Resultados}

Em primeiro momento, a validação do modelo computacional do motor operando com óleo diesel pode ser considerada em função das comparações demonstradas através da Tabela 1. Foram adotados dois valores referenciais para a coleta de dados:20 kW e $50 \mathrm{~kW}$. O percentual de erro apresentado entre os dados coletados e simulados, na maioria dos casos, é inferior à incerteza de medição dos equipamentos. Por exemplo, para $20 \mathrm{~kW}$, a maior variação está no valor simulado para a pressão de exaustão, que difere em $23 \%$ da pressão medida experimentalmente. A menor variação entre experimento e simulação é apresentada no fluxo de massa de ar, sendo inferior a $0,1 \%$. Para as observações em $50 \mathrm{~kW}$, as variáveis comportaram-se de modo similar, garantindo que os resultados obtidos através do modelo assemelham-se com os experimentais.

A cada alteração executada em termos de substituição de combustíveis, realizaram-se novas avaliações entre modelo e experimento. A fim de manter a rotação do motor, o aumento no consumo em massa de álcool e a necessidade de aumento na temperatura do ar admitido, contribuem para a queda no rendimento global do motor. 
Figura 3 - Modelo computacional para o motor Cummins 4BT - 3.9G4 operando com Diesel

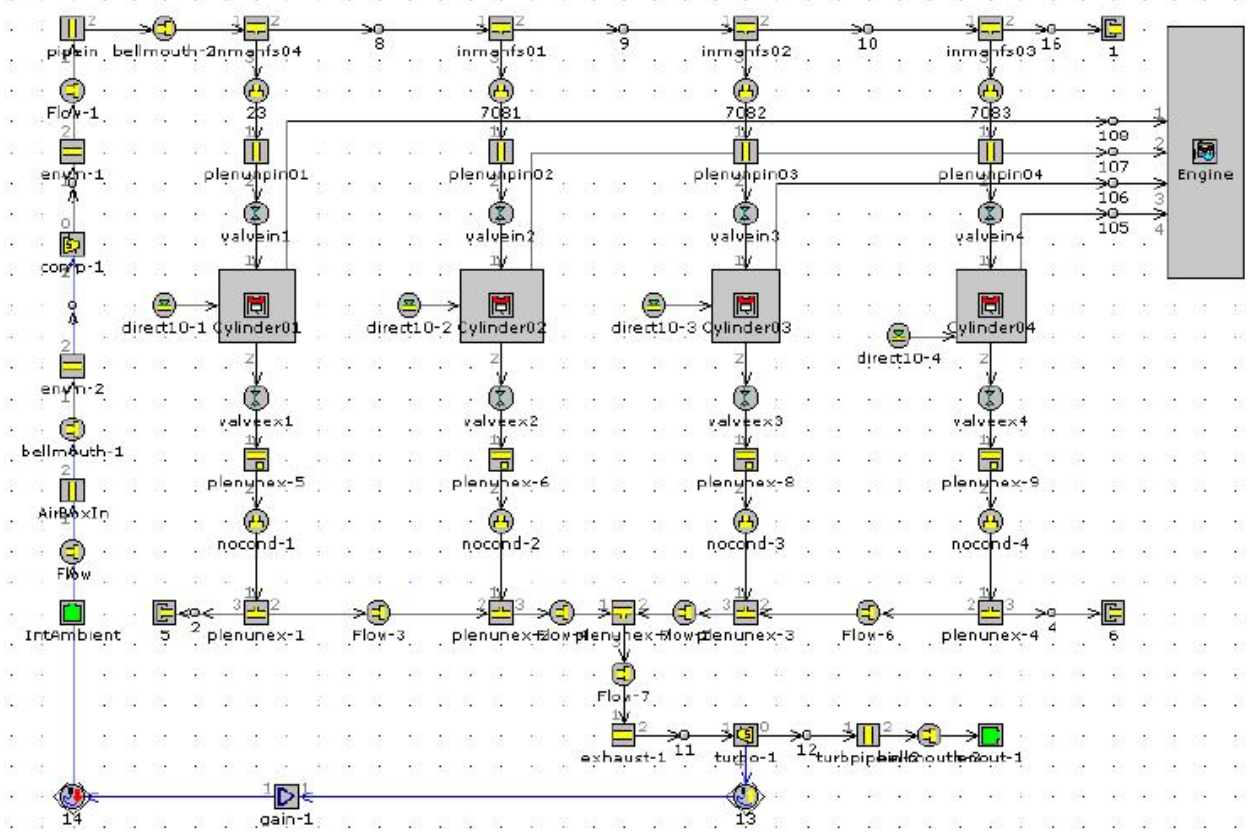

Fonte: o próprio autor

Brambila (2006) cita que o consumo específico de combustível de um motor operando com etanol tende a ser em torno de 55\% maior em comparação à utilização de diesel. Entretanto, estes valores foram potencializados na prática, visto que, para fins de cálculo, considera-se que a combustão seja realizada de forma estequiométrica. A Figura 4 representa valores experimentais de consumo de combustível para quatro condições distintas. Como mostrado pela linha de tendência, o aumento do consumo de combustível pode ser considerado linear com o acréscimo de carga, tanto para operações utilizando etanol quanto com diesel.

Figura 4 - Valores experimentais de consumo de combustível (1/h) para diferentes cargas e combustíveis.

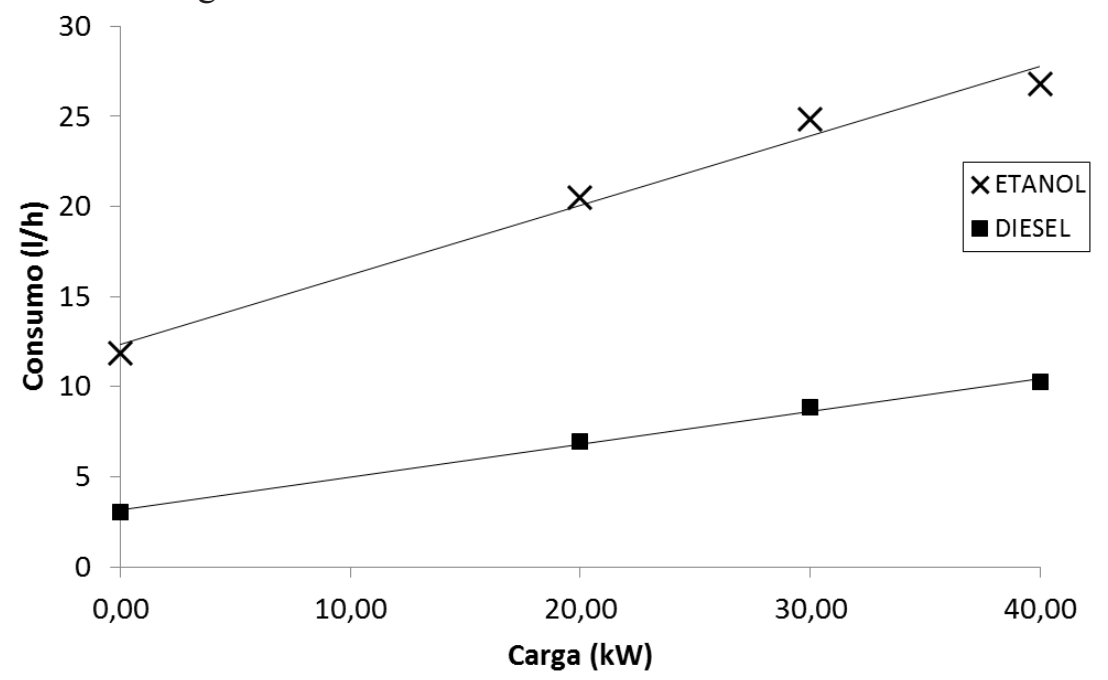

Fonte: o próprio autor 
Tabela 1 - Diferentes parâmetros adquiridos experimentalmente e simulados através de software.

\begin{tabular}{|c|c|c|c|c|}
\hline \multirow{2}{*}{ Variável } & \multicolumn{2}{|c|}{$20 \mathrm{~kW}$} & \multicolumn{2}{|c|}{$50 \mathrm{~kW}$} \\
\hline & Simulado & Medido & Simulado & Medido \\
\hline $\begin{array}{l}\text { Potência Líquida } \\
\qquad(\mathrm{kW})\end{array}$ & 21,69 & 20 & 51,95 & 50 \\
\hline $\begin{array}{c}\text { Consumo de } \\
\text { combustível (g/s) }\end{array}$ & 1,82 & 1,73 & 2,97 & 2,81 \\
\hline BSFC (g/kW.h) & 302,07 & 311,4 & 205,95 & 202,32 \\
\hline MAF (kg/h) & 300,24 & 300,6 & 423,53 & 424,8 \\
\hline Lambda & 3,01 & 3,18 & 2,61 & 2,76 \\
\hline $\begin{array}{c}\text { Pressão no } \\
\text { cilindro (MPa) }\end{array}$ & 7,68 & 7,07 & 9,97 & 9,65 \\
\hline $\begin{array}{c}\text { Pressão na } \\
\text { admissão (kPa) }\end{array}$ & 150 & 140 & 210 & 200 \\
\hline $\begin{array}{c}\text { Pressão na } \\
\text { exaustão (kPa) }\end{array}$ & 210 & 170 & 140 & 180 \\
\hline $\begin{array}{l}\text { Temperatura } \\
\text { no coletor de } \\
\text { admissão }\left({ }^{\circ} \mathrm{C}\right)\end{array}$ & 70,2 & 64,7 & 106 & 114 \\
\hline $\begin{array}{l}\text { Temperatura no } \\
\text { coletor de escape } \\
\left({ }^{\circ} \mathrm{C}\right)\end{array}$ & 382 & 327 & 428 & 470 \\
\hline
\end{tabular}

Fonte: o próprio autor

A partir dos resultados apresentados na Figura 4, a Tabela 2 apresenta um comparativo dos custos de operação para os dois combustíveis em quatro diferentes condições de carga imposta ao gerador. Foram considerados dois contextos distintos. Em um deles, o combustível é comprado pelo consumidor, utilizando como referência os valores registrados pela Agência Nacional do Petróleo (ANP), e em outro o combustível é produzido pelo consumidor, tendo como parâmetro os números obtidos da literatura. O segundo caso pode ser justificado pela crescente aplicação de grupos geradores de energia elétrica com motores de combustão em pequenas propriedades rurais.

Considerando os valores de venda dos combustíveis da região que apresentou maior amplitude entre os preços para diesel e etanol, a Região Sudeste, o uso do etanol não se apresentou viável. Entretanto, se considerados os valores sugeridos por Cabello (2005) para a produção de etanol oriundo do aipim e da cana-de-açúcar em pequenas usinas, a alternativa se torna economicamente atrativa. Devido a inexistência de valores mais recentes de literatura, os valores estudados por Cabello em 2005 foram atualizados pelo índice IGP-M de 2005 para 2015, e assim utilizados na Tabela 2 para comparação ao custo de operação com o etanol e diesel fornecidos nos postos. Com isso, os valores citados para a produção de etanol a partir do aipim e da canade-açúcar em 2005 tiveram um acréscimo de aproximadamente $68 \%$, passando para $\mathrm{R} \$ 0,736 \mathrm{e}$ $\mathrm{R} \$ 0,659$ respectivamente.

Tabela 2 - Custo de operação para variados combustíveis e condições de carga $(\mathrm{R} \$ / \mathrm{h})$.

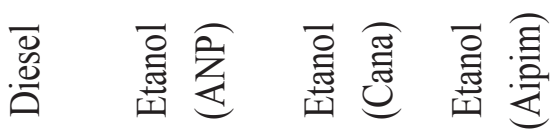

\begin{tabular}{ccccc}
\hline $\begin{array}{c}\text { 0kW (sem } \\
\text { carga) }\end{array}$ & 6,91 & 22,49 & 7,83 & 8,74 \\
$20 \mathrm{~kW}$ & 15,91 & 38,77 & 13,50 & 15,07 \\
& & & & \\
$30 \mathrm{~kW}$ & 20,24 & 47,00 & 16,36 & 18,26 \\
$40 \mathrm{~kW}$ & 23,49 & 50,79 & 17,68 & 19,74 \\
\hline
\end{tabular}

Fonte: o próprio autor

Realizando uma análise sobre a condição de operação de $40 \mathrm{~kW}$, o motor utilizando diesel custaria por dia $\mathrm{R} \$ 655,20$ a menos do que se operasse com etanol adquirido nos postos de combustível. Já ao considerar os valores de literatura para a produção de etanol a partir da cana-de-açúcar ou do aipim, a alteração de combustível tornar-se-ia viável e, diariamente, seriam economizados mais de 100 reais. 
Em se tratando de emissões de gases, os ensaios mostram, através da Figura 5, que a transformação do motor para uso de etanol é favorável à redução das emissões de óxidos de nitrogênio $\left(\mathrm{NO}_{\mathrm{x}}\right)$. Além da estabilidade nas emissões de $\mathrm{NO}_{x}$ com o incremento da carga, observou-se também uma quantidade média aproximadamente dez vezes inferior com o uso de etanol. Este fato está diretamente ligado à redução da temperatura na câmara de combustão.

Figura 5 - Valores experimentais de emissões de NOx(ppm) para diferentes cargas e combustíveis

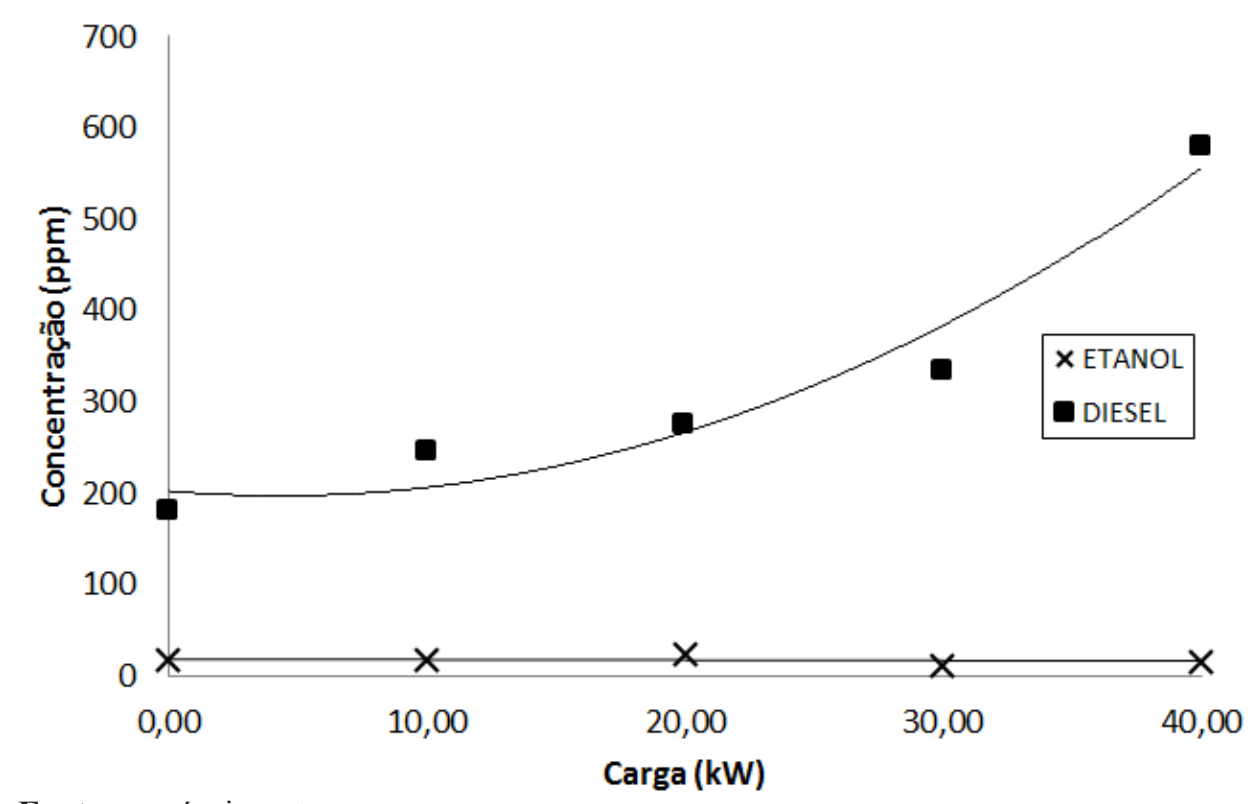

Fonte: o próprio autor

Entretanto, esta redução de temperatura na câmara de combustão resultou num aumento de combustível não vaporizado, havendo depósitos de combustível líquido em espaços onde a frente de chama não atingiria, gerando incremento nas emissões de hidrocarbonetos não queimados (HC). A vaporização do combustível poderia ser intensificada caso a câmara de combustão fosse apropriada para a queima de etanol. O aumento nas emissões de $\mathrm{HC}$ e $\mathrm{CO}$, quando substituído o diesel pelo etanol, foi observado por TSANG (2010), e é fidelizado pelo experimento, de acordo com as Figura 6 e 7, respectivamente. Isto se deve à diferença na mistura ar-combustível existente nos dois casos, onde a queima em motores Diesel é feita com excesso de ar, e em motores Otto, de forma estequiométrica ou até com excesso de combustível em regimes de maior potência. O modo de injeção, direta no ciclo Diesel e indireta no ciclo Otto, também é responsável pelo incremento nas emissões destes dois poluentes. De acordo com Surawski (2010), a substituição gradativa do óleo diesel por etanol, em casos de fumigação, faz com que se reduzam as emissões de material particulado proporcionalmente ao incremento do combustível renovável, principalmente em cargas mais elevadas. Portanto, o material particulado pode ser desconsiderado na análise do motor quando operando unicamente a etanol. 
Figura 6 - Valores experimentais de emissões de HC (ppm) para diferentes cargas e combustíveis

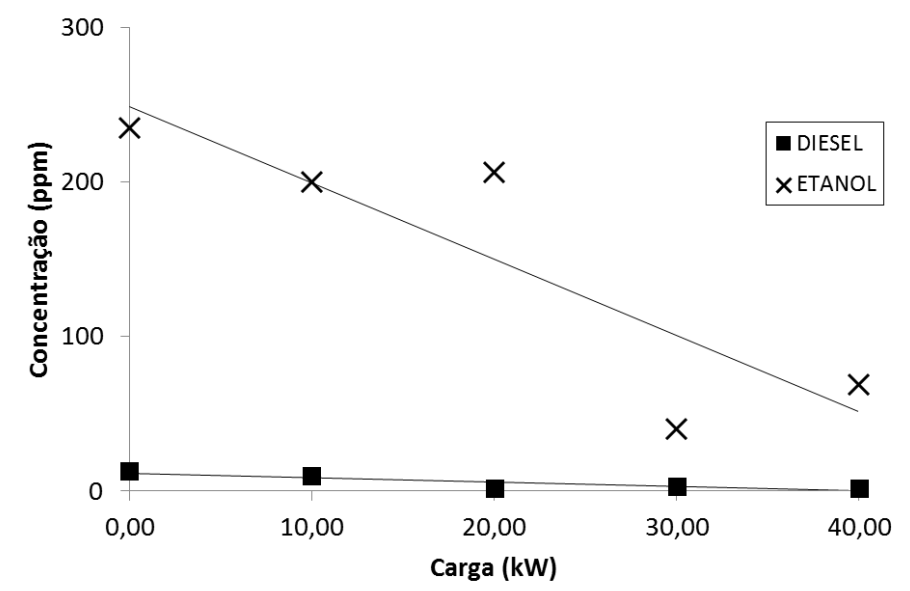

Fonte: o próprio autor

Os pontos e tendências representados nas Figuras 4,5,6 e 7 representam o consumo de combustível e as emissões de poluentes em condições diversas, considerando o uso de etanol e de diesel. Para cada um dos casos fora estabelecido o coeficiente de correlação entre os valores obtidos para etanol e diesel, apontando para a comportamento dos dados. Em termos de consumo, o valor de correlação de 0,997 apresenta uma forte correlação, onde o acréscimo no volume consumido é diretamente proporcional para o diesel e etanol, isto é, a medida que aumenta o volume consumido de diesel aumenta também o volume consumido de etanol, a medida que um deles diminui, o outro também diminui. As emissões de $\mathrm{HC}$ e $\mathrm{CO}$ (com valores de correlação 0,670 e 0,596, respectivamente), apresentaram associações moderadas, que embora sendo diretamente proporcionais, não apresentam alto grau de correlação. A fraca correlação $(-0,233)$ existente entre os dados obtidos experimentalmente para as emissões de NOx pode ser devida a variações no processo de medição, uma vez que o aparelho utilizado nas medições apresenta incerteza de 5\% nos dados coletados.

Figura 7 - Valores experimentais de emissões de CO (ppm) para diferentes cargas e combustíveis

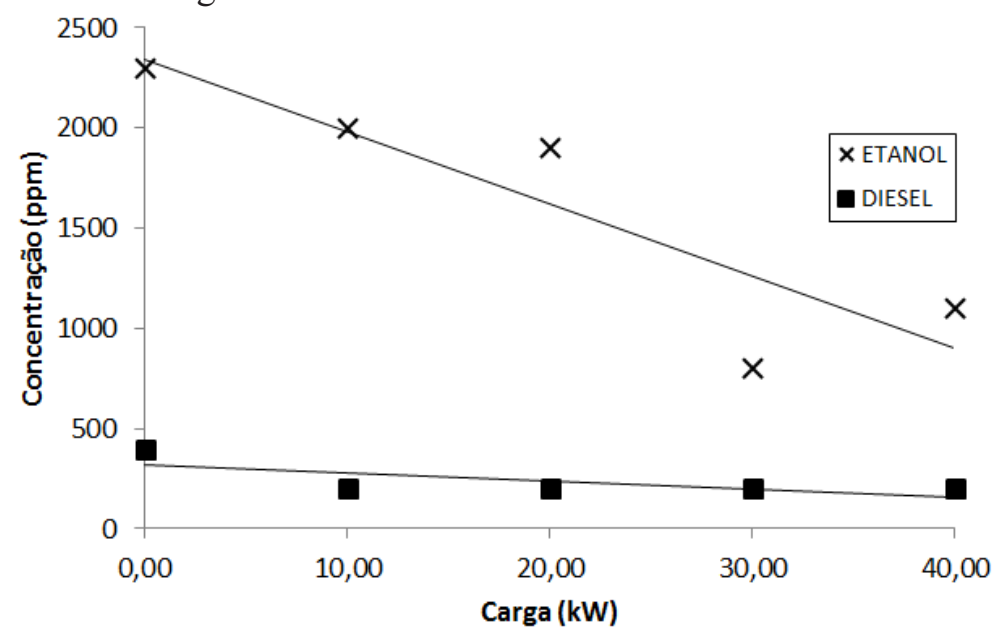

Fonte: o próprio autor 


\section{Conclusões}

A possibilidade de utilização do etanol em motores de combustão interna, responsáveis pela geração de energia elétrica, deve ser considerada. Além de renovável, o combustível contribui significativamente para a redução das emissões de $\mathrm{NO}_{\mathrm{x}}$, podendo ser favorável também às emissões de materiais particulados. Gases como $\mathrm{HC}$ e $\mathrm{CO}$ tiveram seu incremento justificado pela adaptação realizada no motor, o qual não fora projetado para operar cometanol.A tendênciaé que esse incremento tenha menor expressividade em câmaras de combustão dedicadas à queima deste combustível, sendo a posição dos eletro-injetores de etanol contribuinte para este acréscimo de emissões de $\mathrm{HC}$, uma vez que o posicionamento perpendicular à parede do coletor, dificulta a vaporização do combustível. Portanto, em termos ambientais, o etanol pode ter contribuição expressiva na redução dos gases nocivos oriundos da combustão. Os motores atuais, mesmo os produzidos para a utilização de tal combustível, não exploram adequadamente as propriedades do etanol, fazendo com que seu uso na geração de energia elétrica seja inviabilizado. Estudos evidenciam ser possível aumentar a eficiência destes motores, atingindo, em alguns casos, números próximos aos dos motores a óleo diesel (aproximadamente 40\%), sem alterações significativas nos projetos iniciais. Entretanto, alternativas podem ser responsáveis por reverter este quadro, não somente no que tange a alterações de projeto dos motores, mas também na obtenção de combustíveis a custos inferiores, como o caso da produção de etanol em micro usinas para consumo local. Assim sendo, um motor originalmente projetado para operar com ignição por compressão pode utilizar etanol como combustível, se realizadas as alterações mecânicas necessárias. Entretanto, devido ao incremento intrínseco no consumo de combustível, a viabilidade de utilização do etanol fica dependente do custo de obtenção deste produto.

\section{Referências}

AJAV, E. A., SINGH, B., BHATTACHARYA, T. K. Performance of a stationary diesel engine using vapourized ethanol as supplementary fuel. Biomass Bioenergy, v. 15, n. 6, p. 493-502, 1998.

. Experimental study of some performance parameters of a constant speed stationary diesel engine using ethanol-diesel blends as fuel. Biomass Bioenergy, v. 17, n. 4, p. 357-365, 1999.

AGÊNCIA NACIONAL DO PETRÓLEO, GÁS NATURAL E BIOCOMBUSTÍVEIS - ANP. Resolução $n^{\circ}$ 36. Rio de Janeiro, RJ, 2005.

. Resolução $n^{\circ}$ 65. Rio de Janeiro, RJ, 2011.

Sistema de levantamento de preços. Rio de Janeiro, RJ, 2014.

BARROS, M.; GUIMARÃES, Z. O problema da geração a diesel. Disponível em: <http:// www.oeco.com.br/convidados/64-colunistasconvidados/22041-o-problema-da geracao-adiesel?format=pdf $>$, 2010. Acesso em: 14 nov. 2013.

BERNARDES, J. Gerador de eletricidade aumenta impacto da emissão de poluentes. Agência USP de Notícias, Abril 2007. Disponível em: $<$ http://www.usp.br/agen/?p=6044>. Acesso em 19 nov. 2013.

BRAMBILA, J.A. Estudo experimental e simulação termodinâmica de desempenho em um motor de combustão interna operando com diesel e etanol. Dissertação (Mestrado em Engenharia Mecânica) Escola Politécnica da Universidade de São Paulo, São Paulo, 2006.

BRASIL. Ministério de Minas e Energia. Balanço energético nacional-BEN. Brasília, 2014.

BUSTAMANTE, M. Até 2030, emissões dos setores de transporte e energia podem aumentar até 97\%. Blog do clima, Setembro 2013. Disponível em <http://planetasustentavel.abril.com.br/ blog/ blog-do-clima/2013/09/10/ate-2030-emissoes-dossetores-de-transporte-e-energia-podem-aumentarate-97/>. Acesso em: 16 fev. 2015. 
CABELLO, C. Produção de álcool da mandioca. Botucatu, 2005.

CENTRO DE CIÊNCIA DO SISTEMA TERRESTRE - CCST. Mudanças no clima do Brasil até 2100. 2013. Disponível em: <http:// www.ccst.inpe.br/destaques1/mudancas-no-climado-brasil-ate-2100/>. Acesso em: 22 out. 2014.

CUMMINS ${ }^{\circledR}$ Inc. 4BT3.9-G4 Engine Performance datasheet, 2004.

DEPARTAMENTO NACIONAL DE TRÂNSITO - DENATRAN. Quantidade de veículos por município. Brasília, outubro de 2014.

HEYWOOD, J. B. Internal combustion engines fundamentals. 2. ed. New York: McGraw-Hill, 1988.

INSTITUTO BRASILEIRO DE GEOGRAFIA E ESTATÍSTICA - IBGE. Estatística da produção agrícola. 2012.

KOHLHEPP, G. Análise da situação da produção de etanol e biodiesel no Brasil. Estudos Avançados, São Paulo, v. 24, n. 68, p. 224-253, 2010.

NOGUCHI, N., TERAO, H., SAKATA, C. Performance improvement by control of flow rates and diesel injection timing on dual-fuel engine with ethanol. Bioresour Technol. v. 56, n. 1, p:3539, 1996.

RIZATO, M. Potencial econômico da produção de álcool de mandioca no norte do Brasil. In: CONGRESSO BRASILEIRO DA MANDIOCA, 13., Local, 2009. p. 767-771.

SELEGHIM JUNIOR., P.; POLIKARPOV, I. Desafios para transformar conceitos em realidade. Scientific American Brasil, n. 87, p. 32-37, 2009.

SURAWSKI, N. C.; MILIEVIC, B.; ROBERTS, B. A.; MODINI, R. L.; SITU, R.; BROWN, R. J.; BOTTLE, S. E.; RISTOVSKI, Z. D. Particle Emissions, Volatility, and Toxicity from an Ethanol Fumigated Compression Ignition Engine. Environment Science Technology. v. 44, p. 229235, 2010.
TSANG, K. S., ZHANG, Z. H., CHEUNG, C.S., CHAN, T. L. Reducing emissions of a diesel engine using fumigation ethanol and a diesel oxidation catalyst. Energy \& Fuels, v. 24, p. 6156-6165, 2010.

VIEIRA JUNIOR, P. A.; VIEIRA, A. C. P.; BUAINAIN, A. M.; LIMA, F.; SILVEIRA, J. M. F. J. Produção brasileira de cana-de-açúcar e deslocamento da fronteira agrícola no estado do Mato Grosso. Informações Econômicas, SP, v. 38, n. 4, p.58-77, 2008.
Recebido em 19 Junho, 2015 - Received on June 19, 2015 Aceito em 28 Outubro, 2015 - Accepted on October 28, 2015 
